\title{
Research on the Collaborative Management of Industrial Design
}

\author{
Yujia Liu ${ }^{1, a}$, Chunxiao $\mathrm{Cao}^{2, \mathrm{~b}}$ \\ ${ }^{1}$ School of Mechanical Engineering, Shandong University, Jinan 250061, China; \\ ${ }^{2}$ School of Art, Shandong University (Weihai), Weihai 264209, China. \\ a18867872@qq.com, b3210366@qq.com
}

Keywords: industrial design; collaborative management; information technology; Parallel Design.

\begin{abstract}
Industrial design collaborative management is an advanced design concept based on the information network environment is the main technical means of manufacturing quick response to market demand, and constantly introduce new products and rapid development. This paper mainly introduces the synergy management concept, characteristics and major industrial design. Through the collaborative management of industrial design can shorten the development cycle, improve the quality and efficiency of design, reduce the product cost, and increase the competition ability of enterprise.
\end{abstract}

\section{Introduction}

The role of computer in industrial design is essential. In the industrial design, the use of computer aided technology has greatly improved the design ability and drawing quality, shorten the product development cycle. At the same time, the development of computer and information technology of design means will lead to the change of industrial design thought and management. But in the current mode of the industrial design, product design department and the production department are often fragmented, mutual cooperation exists some problems. Enterprise "information isolated island" situation is serious, information scattered in various departments within the enterprise, can not be shared with each other. Therefore, enterprises must break the previous design mode, establish information for industrial design oriented collaborative management processes and management mode, makes the product design, development, manufacturing, marketing and after-sales service and fast information flow and effective management. Product collaborative design management is to adapt to the information society in the designer's work, to the designers to bring the design process of change and the overall improvement of the efficiency of the work.

\section{Basic Concepts of Collaborative Management of Industrial Design}

Industrial design collaborative management is based on the network environment presents a kind of advanced design concept, the purpose is under the support of computer network technology, communication technology and database technology, organized a number of science and technology personnel across geographical and time constraints, at the same time to participate in the design, consultation and discussion, collaborative design and development of industrial products. In the collaborative management, reasonable and effective task planning can shorten the product development cycle, improve the design quality, and enhance the comprehensive competitiveness of enterprises.

Collaborative management of industrial design is not only a process of system work and resource sharing, but also a process of management, through the management to improve the product design and development process, so as to improve product quality. There are scholars collaborative management of industrial design is under the support of computer, the collaborative design personnel around a design project, each bear the corresponding part of the design task, collaborative interaction were design work, and finally got to meet the requirements of the design results of a design method. The collaborative management of industrial design is not a simple design or creation, but a lot of new methods, new technologies, new ideas, and new modes of modern design. The collaborative 
management of industrial design is the inheritance and development of the basic idea of concurrent design.

Many scholars have defined the concept in the research of collaborative design management. Collaborative design is defined by two or more than two design subject, through a certain collaborative mechanism and mutual information exchange, to complete the design method of specific design objectives. Some scholars believe that collaborative design is not only a process of system work and resource sharing, but also a process of management, through the management to improve the product design and development process, so as to improve product quality. There are scholars collaborative design is under the support of computer, the collaborative design personnel around a design project, each bear the corresponding part of the design task, collaborative interaction were design work, and finally got to meet the requirements of the design results of a design method. Recently, there is a definition of collaborative design is a design concept, it refers to a number of participants in the design environment of computer support, to work together to complete the design process of the entire project.

\section{The Characteristics of Collaborative Management of Industrial Design}

Compared with the traditional design process, the collaborative management of industrial design has the following characteristics:

The first is group. And traditional design activities, collaborative design usually has two or more than two main design, the design between subjects tend to be independent of each other and each has a certain professional knowledge and design experience, the final design results is multi subject design collective wisdom crystallization.

The second is synergy. Due to the synergic design group. It requires a number of the main design coordination to complete the design task, which requires a management system to effective coordination between the various design main bodies of work and coordinate product development resources.

Once again it is common. Traditional design activities often use top-down design order, the design intention is clear, the process is clear. And collaborative design is different, it requires participating in the design of a number of subjects in parallel to design activities, we want to achieve is a common design objectives.

Finally it is heterogeneous. Collaborative design usually involves different geographical locations, the number of enterprises, because the enterprise work platform is not exactly the same. Therefore, collaborative design also has a heterogeneous; it is mainly reflected shared among enterprises and departments in the data source, problem solving way and the use of software and hardware and so on.

\section{The Difference and Connection Between The Collaborative Development of Industrial Design and Serial Design and Parallel Design}

Serial design is a sequential development process, which is a linear product design method. In the design process, developers as required after the completion of their work will be given the results of the next section, if there is a problem is to return to, aside from the problems found in the assembly and in the manufacturing stage can propose amendments, between the whole development process generally does not exist to exchange information, resulting in development projects tend to their role in the whole development process of lack of clear understanding, upstream of the design activities can not be very good considering the downstream design requirements. The design results are many unreasonable factors. Product development to design - processing - test modifications to such a cycle, and likely will repeat this cycle in the development process, makes the product development cycle continues to increase and improve the product development cost.

Parallel design is a kind of product development mode, which is produced by the disadvantages of serial design. It is a revolution of traditional serial development. During this development model of the product and its related process, the design of the parallel, integration it requires the product 
developers to consider all kinds of factors that affect the life cycle of the product from the beginning of the design, and the integration process is managed and controlled from the point of view of global optimization. Parallel design is through restructuring and improving the product development process in order to optimize the product development process, ensure designers in the product development process to make the correct decision, effectively reduce the design modification to shorten the development cycle.

Collaborative design management mode is refers in computer supported collaborative virtual environment, will be distributed in different locations, different areas of design personnel around a common goal of the design, each bear the corresponding part of the design task, interactive, collaborative design work and finally to meet the requirements of the design results. The industrial design development model emphasizes the design community, cooperation, common and heterogeneous, in different enterprises; different departments' designers to synchronous or asynchronous participate in design work, so as to improve the quality and efficiency of product design, further enhancing the competition ability of the enterprise.

As can be seen from the above content, industrial design collaborative management and concurrent design is the improvement of traditional product development model, but both in content or larger difference, collaborative design essence is concurrent design further. At the same time, regardless of the collaborative design and concurrent design, cooperative work environment in the specific implementation, from the original design team meetings, design personnel face to discuss exchange specific collaborative work, development to now the computer supported cooperative work, in the actual design process both to use, is intertwined with each other.

\section{On the Basis of Collaborative Management of Industrial Design and Research}

Today's users the functions of the product demand increasingly diversified and personalized, which on the product design put forward higher requirements, the pressure of market competition make people more and more attention to product manufacturing, assembly and users and product design between the coordination problems. At this time with the traditional serial development model can not keep up the pace of the development of the times, enterprises urgently need a new development model to effectively improve the ability of product development, this development model should not only to avoid the malpractices existing in the traditional model, but also be able to support enterprises of advanced operation and management, collaborative design is in this environment.

Collaboration is a profound concept, it emphasizes the coordination and cooperation between individuals, fully embodies the dialectical point of view. In the long river of human history development, everywhere there is existence of a cooperative, small to the ordinary people of housing construction, the building of the Great Wall, which embody the synergy theory.

1986, scientists in the United States Malone proposed framework of coordination theory and the theory of comprehensive study of the such as operations research, organization theory, computer science, economics, management science, linguistics, psychology, etc. within the various disciplines or related disciplines on the collaborative aspects of thought and the method, will co as a managerial behavior relation, such as enterprise resource optimization and sharing, the relationship between the production and consumption process, different people between relations, task and sub task between relations. The theory discusses the characteristics of different types of coordination, and puts forward the method and technical management of these related points. The establishment of cooperative theory makes people's understanding of synergy from the perceptual to the rational, the formation of a new science.

Design is often a multi-source complex process. In order to achieve a networked product optimization design, usually to introduce many kinds of design methods and technology to achieve the purpose of the design and a design problem containing many different design task and multi number according to type. Such as complex product design often requires comprehensive 
consideration of function, structure, process, material, such as the appearance of a knowledge, but also take into account the product performance, weight, volume, development time and production cost etc. the constraint conditions, the various factors interaction constraints. Therefore, the design of the problem is a typical of the distribution, dynamic characteristics of the group to solve the problem. In the design process of network products, not only related to the product related to the various fields of knowledge or expertise, but also related to the multi domain knowledge, experience, data processing and utilization. The complexity of the design process is the most direct demand for collaborative design.

Due to the rapid development of information network technology, especially the rapid development of computer technology and communication technology, the integration of collaboration and design provides a strong support. Collaborative design is in this context, a product of modern design mode. Collaborative design essence is the concurrent design further, it is refers to under the computer virtual collaborative environments, different in different areas and different levels of cooperation around a common project, bear the corresponding part of the design task, parallel, interactive and cooperative in design, finally got in line with the requirements of the design results. It emphasizes collaborative participants to design the work mode of the group, the designers of different locations, management personnel, construction personnel can synchronously or asynchronously in design work, so as to shorten the development cycle, improve the quality and efficiency of design, reduce the product cost, increase the competition ability of enterprises.

\section{Conclusion}

Industrial design collaborative management will be the main technical means of manufacturing quick response to market demand, and constantly introduce new products, win the competition, survival and development. Industrial design collaborative management goal is to make the product design and manufacturing in a timely manner through computer network serial or parallel. It supports multi subject design in distributed and heterogeneous environment, collaborative design; provide a feasible solution for the enterprise. Collaborative management of industrial design is a collaborative engineering environment model of product development, in the development environment, scattered in various parts of the products collaborative design project engineer, product collaborative design personnel, product collaborative design audit personnel at all levels to rely on CAD software design, product collaborative design information resources, computer software and hardware resources such as product development together to accomplish the goal of product design.

Industrial design collaborative management to be successful, to achieve requirements of design target, quality, the provisions of the time limit, the approved budget, etc., must be full process, full range planning, organization, coordination the whole design project; must do a good job in the entire product collaborative design project management. Therefore, do a good job in project management is directly related to the success of product collaborative design. How to better to carry out the product collaborative design project management has become one of the important contents of product collaborative design research.

\section{References}

[1]. Wang Yantao, Huang Kezheng "Research on computer collaborative product design” Journal of Qiingdao University, pp.80-82, June 2003.

[2]. Tian Ling, Tong Bingshu "The theory and practice of collaborative design of networked products” Computer integrated manufacturing system, pp.38, December 2002.

[3]. Zhang Li, "Research on Collaborative Innovation of new energy industry in Yangtze River Delta” Macro economic management, pp.39-41, February 2010. 
[4]. Xu Qingrui "Research on improving the innovation ability of small and medium enterprises by applying comprehensive innovation management” Journal of Management Engineering, pp.1-6, January 2009.

[5]. Yin Guofu, Chen Yonghua "The technology and application of enterprise information system based on Intranet” computer science, pp.59-63, March 1999.

[6]. Liu Shenyuan, “Online project management and collaborative work system” Construction supervision, pp.64-65, April 2002.

[7]. Wang Jian, "Project management system coordination and implementation" Construction technology Design, pp.20-21, May 2006.

[8]. Kong Jianshou, Shen Chunlong "Research on project management system for distributed product development” Mechanical Science and technology, pp.770-772, May 2001.

[9]. Liu Guanzhong, “Innovation of original design and industrial design industry chain” information of manufacturing industry in China, pp.44-48, November 2008. 